\title{
Model Problem Based Learning Berbantuan Blended Learning terhadap Kesadaran Metakognitif Mahasiswa pada Materi Spektroskopi Atom
}

\author{
Silvi Octaviani Asmi ${ }^{1}$, Surjani Wonorahardjo ${ }^{1}$, Hayuni Retno Widarti ${ }^{1}$ \\ ${ }^{1}$ Pendidikan Kimia-Universitas Negeri Malang
}

\begin{tabular}{l}
\hline \hline INFO ARTIKEL \\
\hline Riwayat Artikel: \\
Diterima: 26-04-2019 \\
Disetujui: 23-06-2019 \\
\hline
\end{tabular}

\section{Kata kunci:}

problem based learning; blended learning:

metacognitive awareness; problem based learning; blended learning; kesadaran metakognitif

\begin{abstract}
ABSTRAK
Abstract: This study aims to determine differences in metacognitive awareness of students who are taught with a problem based learning model based blended learning on the material of the atomic spectroscopy. This study used a metacognitive awareness questionnaire instrument that has content validation of $95.28 \%$ with very good criteria and a Cronbach Alpha reliability coefficient of 0.884 in the high category. The research was conducted at the Universitas Negeri Malang in two classes. The experimental class which was taught by the problem based learning model assisted by blended learning and the control class that was taught with a problem based learning model. The results showed a statistically significant difference in students' cognitive knowledge and metacognitive awareness in both study classes $(\alpha=0.050)$.
\end{abstract}

\begin{abstract}
Abstrak: Penelitian ini bertujuan untuk mengetahui perbedaan kesadaran metakognitif mahasiswa yang dibelajarkan dengan model problem based learning berbantuan blended learning pada materi spektoskopi atom. Penelitian ini menggunakan instrumen angket kesadaran metakognitif yang memiliki validasi isi $95.28 \%$ dengan kriteria sangat baik dan koefisien reliabilitas Alpha Cronbach 0.884 dengan kategori tinggi. Sampel penelitian dilakukan di Universitas Negeri Malang pada dua kelas. Kelas eksperimen yang dibelajarkan dengan model problem based learning berbantuan blended learning dan kelas kontrol yang dibelajarkan dengan model problem based learning. Hasil penelitian menunjukkan adanya perbedaan yang signifikan secara statistik terhadap pengetahuan kognitif dan kesadaran metakognitif mahasiswa di kedua kelas penelitian $(\alpha$ $=0.050)$.
\end{abstract}

\section{Alamat Korespondensi:}

\section{Silvi Octaviani Asmi}

Pendidikan Kimia

Universitas Negeri Malang

Jalan Semarang 5 Malang

E-mail: octavianiasmisilvi@gmail.com

Ilmu kimia merupakan suatu cabang ilmu pengetahuan alam yang mempelajari tentang sifat, komposisi, struktur, perubahan struktur dan komposisi zat, serta energi yang menyertai perubahannya (Licker, 2003). Salah satu cabang ilmu kimia yaitu kimia analitik yang menganalisis kandungan materi atau senyawa secara kualitatif dan kuantitatif (Wonorahardjo, 2013). Analisis kualitatif bertujuan untuk mengetahui komponen apa saja yang terkandung dalam suatu sampel bahan. Selain itu, mencakup dalam penentuan struktur atau gugus fungsi dan sifat-sifat karakteristiknya. Analisis kuantitatif bertujuan untuk menentukan jumlah relatif komponen-komponen penyusun atau sampel bahan. Kandungan materi atau senyawa dapat dianalisis melalui metode analitik. Metode analitik terbagi menjadi dua, yaitu metode konvensional dan metode modern (instrumen). Salah satu metode analisis modern adalah metode analisis spektroskopi atom.

Spektroskopi atom adalah metode analisis kimia secara kuantitatif yang pengukurannya berdasarkan penyerapan cahaya dengan panjang gelombang tertentu oleh atom logam dalam keadaan bebas (Skoog et. al., 1982). Materi spektroskopi atom diajarkan pada matakuliah Analisis Instrumentasi I di Jurusan Kimia Universitas Negeri Malang. Sub bab materi spektroskopi atom salah satunya adalah pengaplikasian instrumen spektroskopi atom dalam kehidupan sehari-hari. Prinsip spektroskopi atom yang bersifat abstrak berdampak pada kesulitan mahasiswa dalam mempelajari cara kerja instrumen spektroskopi atom terkait fenomena-fenomena interaksi antara radiasi elektromagnetik dengan suatu zat, seperti proses abrobsi, emisi, flouresensi, serta bagian dan fungsi dari instrumen hanya berdasarkan bahan bacaan. Materi ini menuntut mahasiswa untuk mengaitkan pembelajaran dalam kehidupan sehari-hari yang mengarahkan pada konstruksi pengetahuan yang lebih luas. Guru sebagai fasilitator memberikan pengalaman belajar kepada mahasiswa dengan mengemukakan suatu masalah atau fenomena yang ada dan dialami mahasiswa dalam kehidupan sehari-hari. Kegiatan pembelajaran menjadi lebih bermakna jika menghadirkan permasalahan yang real sebagai stimulus belajar mahasiswa. Pembelajaran kimia analisis instrumen khususnya pada instrumen 
spektroskopi atom lebih mengarahkan pada konstruksi pengetahuan yang luas dan melatih mahasiswa memecahkan suatu permasalahan secara sistematis. Oleh karena itu, agar mempermudah mahasiswa untuk menemukan konsep secara mandiri perlu adanya penerapan strategi pembelajaran yang berbasis konstruktivisme sehingga dapat memaksimalkan kemampuan berpikir mahasiswa. Salah satu alternatif strategi yang dibutuhkan dalam meningkatkan pemahaman mahasiswa untuk mengonstruksi pengetahuan yang luas adalah penerapan strategi pembelajaran yang berbasis konstruktivistik. Salah satu pembelajaran berbasis konstruktivistik adalah problem based learning.

Problem Based Learning merupakan model pembelajaran yang menyajikan situasi permasalahan autentik dan bermakna yang dapat menumbuhkan rasa ingin tahu mahasiswa untuk melakukan investigasi (penyelidikan) dan inkuiri (Arends, 2012). Mahasiswa dilibatkan dalam memecahkan masalah melalui tahapan-tahapan metode ilmiah dengan melakukan investigasi. Tahapan-tahapan PBL memberikan kesempatan kepada mahasiswa untuk mempertanyakan fenomena yang ada dan aktif membangun pemahaman terhadap konsep spektroskopi atom dengan lebih koheren, fleksibel, dan sistematis. Hal ini sesuai dengan pernyataan Ward, et. al., (2002) yang menjelaskan bahwa PBL merupakan suatu model pembelajaran yang melibatkan mahasiswa untuk memecahkan suatu masalah melalui tahap-tahap metode ilmiah sehingga mahasiswa dapat mempelajari pengetahuan yang berhubungan dengan masalah yang ada dan sekaligus memiliki keterampilan untuk memecahkan masalah sehingga diharapkan dapat meningkatkan hasil belajar mahasiswa. Guru sebagai fasilitator memberikan pengajaran yang menarik sehingga membantu mahasiswa dalam memecahkan masalah. Spektroskopi atom juga memiliki cakupan materi yang luas karena banyak ditemukan penemuan baru sehingga pemanfaatan teknologi internet dalam pembelajaran dapat dilakukan untuk mengakses materi tersebut. Oleh karena itu, perlu mengaplikasikan pengajaran berbatuan teknologi yang salah satunya internet berbasis blended learning.

Blended learning menggabungkan berbagai metode dan strategi pengajaran yang memanfaatkan teknologi virtual. Blended learning dapat diterapkan tidak hanya pada saat proses pembelajaran tatap muka, tetapi juga pada saat kegiatan di luar tatap muka, baik di lingkungan sekolah, di rumah, maupun di tempat lainnya yang ada akses internet (Dobrzanski \& Brom, 2008). Penggunaan pembelajaran dengan blended learning dapat menambah waktu pembelajaran mahasiswa, mempermudah dan mempercepat proses komunikasi antara guru dan mahasiswa (Eklund, Kay, \& Lynch, 2003). Selain itu, blended learning mempunyai keunggulan lain yaitu (1) mahasiswa dapat mengontrol kegiatan belajar secara mandiri melalui feedback langsung (Strambi \& Bauvet, 2003), (2) mahasiswa lebih banyak kesempatan untuk berinteraksi, mendapatkan umpan balik secara langsung sehingga meningkatkan pembelajaran dan kinerja secara mandiri (Schraw, 2007), (3) hasil belajar yang lebih tinggi dibandingkan dengan pembelajaran konvensional (Dzuiban et al., 2004). Media aplikasi yang mendukung sangat diperlukan pada proses pembelajaran blended learning. Salah satunya adalah media terdapat beberapa fitur yang dapat aplikasi Edmodo.

Pada aplikasi Edmodo dimasukkan, di antaranya teks, grafik, animasi, simulasi, audio dan video sehingga dapat membantu guru dan mahasiswa untuk saling berkolaborasi, berbagai ide, berkomunikasi dan berinteraksi (Lahad et al., 2012). Media yang dapat menampilkan video merupakan media yang dapat mengurangi kesulitan bagi mahasiswa untuk menerima materi pembelajaran. Visualisasi konseptual berupa gambar, animasi, video dan analogi sangat membantu mahasiswa dalam memahami materi kimia (Kirna, 2010). Berdasarkan Kurikulum Pendidikan Tinggi (2015) salah satu kompetensi yang harus dimiliki oleh mahasiswa adalah mampu menerapkan pemikiran logis, kritis, sistematis, dan inovatif dalam konteks pengembangan atau implementasi ilmu pengetahuan dan teknologi serta mampu melakukan proses evaluasi diri terhadap kelompok kerja yang berada di bawah tanggungjawabnya, dan mengelola pengembangan kompetensi kerja secara mandiri.

Kompetensi dalam pendidikan saat ini adalah kemampuan untuk bekerja sama dalam kelompok, kemampuan pemecahan masalah, kemampuan untuk mengarahkan diri, berpikir kritis, menguasai teknologi serta mampu berkomunikasi dengan efektif (Kaku, 2011). Menurut Bishop dalam Rusman et. al., (2012), Pendidikan masa mendatang akan bersifat fleksibel, terbuka, dan dapat diakses oleh siapapun yang memerlukan tanpa memandang faktor jenis, usia, maupun pengalaman pendidikan. Hal ini sejalan dengan pendapat Mason dalam Rusman et. al., (2012) bahwa pendidikan mendatang akan lebih ditentukan oleh jaringan informasi yang memungkinkan untuk berinteraksi dan kolaborasi. Pengaruh teknologi informasi dan komunikasi dalam dunia pendidikan semakin terasa sejalan dengan adanya pergeseran pola pembelajaran dari tatap muka yang konvensional ke arah pendidikan yang lebih terbuka dan bermedia. Mahasiswa perlu dibekali dengan pengetahuan, keterampilan, sikap, dan sistem diri untuk mencapai tujuan belajarnya agar menaikkan hasil belajar. Hal utama yang harus ditumbuhkan dalam diri mahasiswa yaitu kemampuan metakognitifnya agar mahasiswa mengetahui seberapa besar keinginan atau minat yang ada dalam diri untuk membuat keputusan belajar dan mencapai pemahaman yang baik guna meningkatnya hasil belajar.

\section{METODE}

Rancangan penelitian adalah eksperimental semu posttest pada dua kelompok (quasi experimental postest). Pemilihan sampel dilakukan dengan teknik convenience sampling pada mahasiswa Universitas Negeri Malang. Diperoleh dua kelas penelitian yaitu kelas eksperimen yang dibelajarkan dengan model problem based learning berbantuan blended learning $(\mathrm{N}=31)$ dan kelas kontrol yang dibelajarkan dengan model problem based learning $(\mathrm{N}=31)$. Angket kesadaran metakognitif ini diberikan di akhir pembelajaran. Skema rancangan penelitian disajikan pada tabel 1. 
Tabel 1. Rancangan Penelitian

\begin{tabular}{ccc}
\hline Subjek & Perlakuan & Postes \\
\hline Kelas Eksperimen & $\mathrm{X}$ & $\mathrm{O}$ \\
Kelas Kontrol & - & $\mathrm{O}$ \\
\hline
\end{tabular}

Keterangan:

$\mathrm{X}$ : Perlakuan dengan membelajarkan model problem based learning berbantuan blended learning

- : Perlakuan dengan membelajarkan model problem based learning

$\mathrm{O}:$ Posttest kedua kelas setelah perlakuan

Rancangan penelitian kesadaran metakognitif menggunakan inventori yang dikembangkan oleh Schraw \& Dennison, yaitu MAI (Metakognitive Awareness Inventory) (Schraw \& Dennison, 1994). Angket yang digunakan adalah angket tertutup dalam bentuk skala sikap dari Likert, berupa pertanyaan atau pernyataan yang jawabannya dalam bentuk skala deskriptif. Alternatif jawaban dengan menggunakan skala Likert terdiri atas lima alternatif jawaban, yaitu sangat setuju (SS), setuju (S), netral (N), tidak setuju (TS), dan sangat tidak setuju (STS). Masing-masing skor jawaban dari pertanyaan yang disediakan yaitu $\mathrm{SS}=5, \mathrm{~S}=4, \mathrm{~N}=3, \mathrm{TS}=2$, STS=1. Skor maksimum angket kesadaran metakognitif adalah 150 dengan 30 butir pernyataan. Kriteria pengukuran kesadaran metakognitif dapat dilihat pada tabel 2.

Tabel 2. Kriteria Pengukuran Kesadaran Metakognitif

\begin{tabular}{cll}
\hline Skala Nilai & \multicolumn{1}{c}{ Kriteria } & \multicolumn{1}{c}{ Uraian Kemampuan } \\
\hline 0 & Belum berkembang & Belum menggunakan metakognitif \\
\hline $1-30$ & Masih sangat berisiko & Belum memiliki kesadaran bahwa berpikir adalah sebuah proses \\
\hline $31-60$ & Belum begitu berkembang & $\begin{array}{l}\text { Belum mampu memisahkan apa yang dia pikirkan dan bagaimana } \\
\text { dia berpikir }\end{array}$ \\
\hline $61-90$ & Mulai berkembang & $\begin{array}{l}\text { Dapat dibantu untuk sadar akan cara berpikirnya sendiri dengan } \\
\text { menggunggah dan mendukung cara mereka berpikir }\end{array}$ \\
\hline $91-120$ & Oke (sudah berkembang baik) & $\begin{array}{l}\text { Sadar dengan cara berpikirnya dan dapat membedakan tahap } \\
\text { elaborasi input dan output dari proses berpikir dan belajarnya. }\end{array}$ \\
\hline $121-150$ & Super (berkembang sangat baik) & $\begin{array}{l}\text { Menggunakan kesadaran metakognitif secara teratur untuk } \\
\text { mengukur proses berpikir dan belajarnya secara mandiri. } \\
\text { Sadar akan banyak macam cara dalam berpikir, mampu } \\
\text { menggunakannya secara lancar dan dapat merefleksikan proses berpikirnya }\end{array}$ \\
\hline
\end{tabular}

\section{HASIL}

Hasil kesadaran metakognitif mahasiswa dianalisis dari angket kesadaran metakognitif yang diadaptasi Schraw \& Dennison yang diberikan kepada mahasiswa kelas eksperimen dan kelas kontrol. Angket kesadaran metakognitif bertujuan untuk mengetahui kemampuan metakognitif mahasiswa untuk mencari informasi seberapa besar keinginan atau dorongan yang ada di dalam diri mahasiswa untuk membuat keputusan dalam pembelajarannya agar dapat mencapai pemahaman tentang materi spektroskopi atom dengan baik. Rekapitulasi data kesadaran metakognitif mahasiswa di kelas eksperimen dan kelas kontrol disajikan pada tabel 3 .

Tabel 3. Rekapitulasi Data Kesadaran Metakognitif Mahasiswa

\begin{tabular}{cccccc}
\hline Kelas & Jumlah Siswa & Total & Standart Deviasi & Rata-Rata & Kriteria \\
\hline Eksperimen & 31 & 3682 & 11,48 & 118,77 & Berkembang baik \\
Kontrol & 31 & 3499 & 10,64 & 112,87 & Berkembang baik \\
\hline
\end{tabular}

Tabel 3 menunjukkan bahwa rata-rata nilai kesadaran metakognitif mahasiswa kelas eksperimen $(118,77)$ yang artinya mahasiswa memiliki kesadaran metakognitif yang sudah berkembang baik. Sementara itu, rata-rata nilai kesadaran metakognitif mahasiswa kelas kontrol $(112,87)$ yang artinya mahasiswa memiliki kesadaran metakognitif yang sudah berkembang baik. Perbandingan nilai rata-rata kesadaran metakognitif mahasiswa yang dirujuk dari tabel 3 disajikan pada gambar 1. 


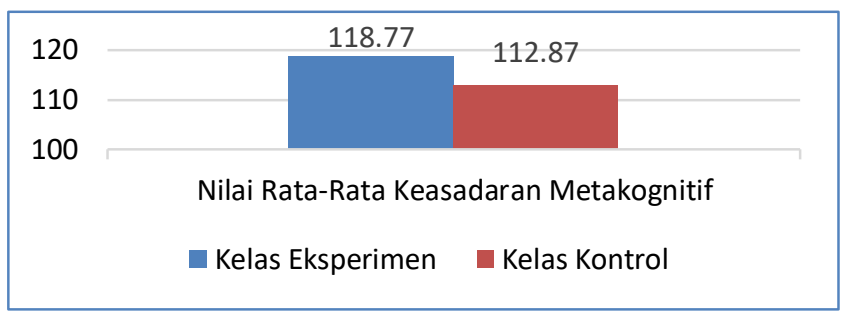

\section{Gambar 1. Perbandingan Nilai Rata-Rata Kesadaran Metakognitif Mahasiswa}

Berdasarkan skor rata-rata dapat dilihat bahwa kedua kelas memiliki rata-rata kesadaran metakognitif yang sudah berkembang baik. Skor rata-rata maksimum kesadaran metakognitif adalah 150 dengan kriteria perkembangan sangat baik. Untuk mengetahui lebih jelas apakah hasil kesadaran metakognititf mahasiswa kelas eksperimen dan kelas kontrol berbeda atau tidak, maka perlu dilakukan uji hipotesis. Sebelum uji hipotesis, data posttest juga harus diuji prasyarat terlebih dahulu, yaitu uji normalitas dan uji homogenitas.

Tabel 4. Hasil Uji Normalitas Data Kesadaran Metakognitif Mahasiswa

\begin{tabular}{|c|c|c|c|}
\hline \multirow{2}{*}{ Kelas } & \multicolumn{2}{|c|}{ Uji Normalitas Kolmogorov-Smirnov } & \multirow{2}{*}{ Kesimpulan } \\
\hline & $\mathbf{N}$ & Signifikansi & \\
\hline Eksperimen & 31 & 0,200 & Normal \\
\hline Kontrol & 31 & 0,200 & Normal \\
\hline
\end{tabular}

Tabel 4 menunjukkan bahwa signifikansi data angket kesadaran metakognitif kelas eksperimen $(0,200)$ besar dari 0,050 dan kelas kontrol $(0,200)$ lebih besar dari 0,050, sehingga dapat disimpulkan bahwa data kesadaran metakognitif kelas eksperimen dan kelas kontrol sama-sama terdistribusi normal. Hasil uji homogenitas data kesadaran metakognitif kedua kelas dapat dilihat pada tabel 5 .

Tabel 5. Hasil Uji Homogenitas Data Kesadaran Metakognitif Mahasiswa

\begin{tabular}{ccc}
\hline Levene Statistik & Signifikansi & Kesimpulan \\
\hline 0,000 & 0,992 & Homogen \\
\hline
\end{tabular}

Tabel 5 menunjukkan bahwa signifikansi data kesadaran metakognitif kedua kelas $(0,992)$ lebih besar dari 0,050 , sehingga disimpulkan bahwa data kesadaran metakognitif kedua kelas memiliki varians yang homogen. Berdasarkan hasil uji prasyarat data pretes dan data kesadaran metakognitif pada kelas eksperimen dan kelas kontrol, kedua kelas tersebut terdistribusi normal dan memiliki varians yang homogen. Oleh sebab itu, uji hipotesis yang sesuai digunakan adalah uji Independent Sample $t$-Test dengan taraf kepercayaan $95 \%(\alpha=0,050)$. Hasil uji dengan bantuan program SPSS 24 for windows ditunjukkan pada tabel 6.

Tabel 6. Hasil Uji Independent Sample t-Test Kesadaran Metakognitif

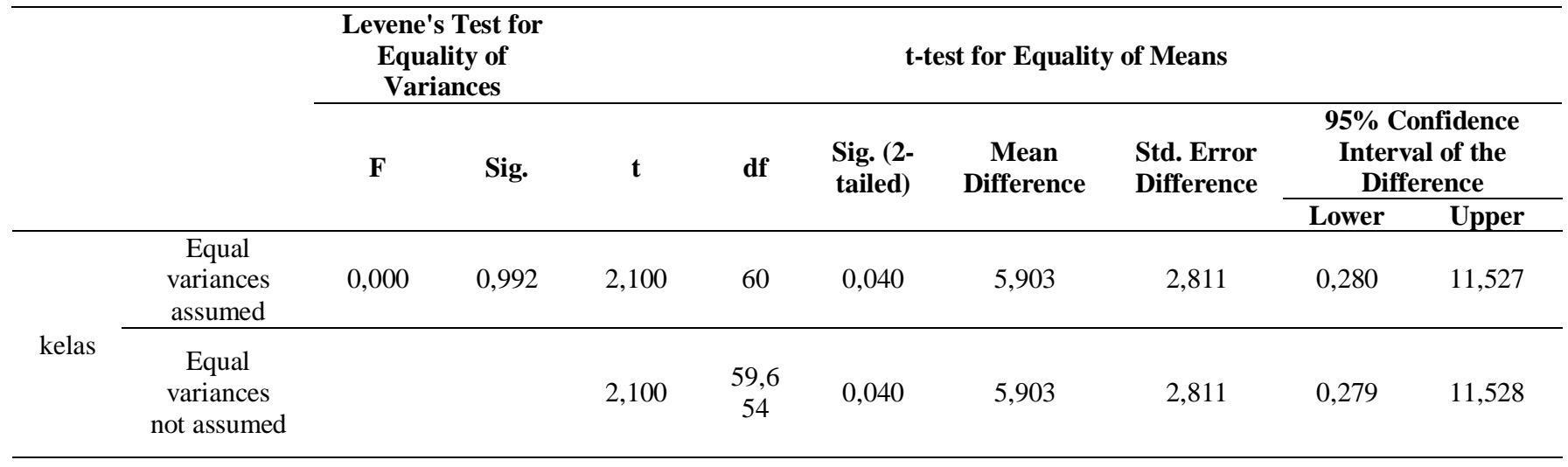

Hasil uji hipotesis dengan uji Independent Sample $t$-Test memiliki nilai signifikansi $(0,040)$ lebih kecil dari 0,050, maka $\mathrm{H}_{0}$ ditolak. Oleh karena itu, dapat disimpulkan kesadaran metakognitif kelas eksperimen yang dibelajarkan dengan model problem based learning berbantuan blended learning lebih tinggi daripada kelas kontrol yang dibelajarkan dengan model problem based learning. 


\section{PEMBAHASAN}

Perpaduan antara Blended Learning dengan Problem Based Learning memiliki landasan teoretis. Blended Learning dan Problem Based Learning saling mendukung dalam pembelajaran tatap muka maupun pembelajaran daring (Delialioğlu, 2012; Delialioğlu \& Yildirim, 2007). Problem Based Learning mengikuti prinsip teori pembelajaran konstruktivisme yang menggunakan pendekatan pembelajaran berpusat pada aktivitas belajar siswa (Hmelo-Silver, 2004). Hal tersebut dapat dijadikan sebagai dasar perpaduan teoretis antara blended learning dan PBL, bukti bahwa keduanya saling mendukung satu dengan yang lain dalam menciptakan lingkungan pembelajaran yang dapat menarik minat mahasiswa sehingga dapat meningkatkan hasil belajar mahasiswa.

Berdasarkan tabel 6 diperoleh hasil uji hipotesis dengan uji Independent Sample t-Test memiliki nilai signifikansi 0,040 lebih kecil dari 0,050, dapat disimpulkan bahwa ada perbedaan kesadaran metakognitif mahasiswa yang dibelajarkan dengan model problem based learning berbantuan blended learning dan model problem based learning. Artinya, bahwa model problem based learning berbantuan blended learning memberikan dampak yang signifikan terhadap kesadaran metakognitif mahasiswa dibandingkan model problem based learning. Hasil tersebut disebabkan karena terdapat pembelajaran dengan pemanfaatan internet yang sering disebut e-learning atau pembelajaran blended learning.

Blended learning merupakan perpaduan pembelajaran secara tatap muka dan daring untuk memaksimalkan proses pembelajaran. Pembelajaran berbantuan blended learning tidak hanya diterapkan pada saat proses pembelajaran tatap muka dikelas tetapi juga dapat diterapkan pada saat kegiatan di luar tatap muka yang ada akses internetnya. Pembelajaran daring mengutamakan interaksi antara mahasiswa dengan mahasiswa ataupun mahasiswa dengan guru secara diskusi daring yang dilakukan mahasiswa dalam kelompok kecil ataupun diskusi daring bersama seluruh mahasiswa dikelompok besar sehingga dapat memberikan kesempatan mahasiswa untuk menerapkan konsep yang telah diperoleh dengan waktu yang tidak terbatas dalam pertemuan kelas. Menurut Sindu (2013) suasana pembelajaran daring dapat melatih mahasiswa lebih aktif dalam pembelajaran, mahasiswa membuat perancangan dan mencari materi dengan usaha sendiri.

Mahasiswa yang memiliki kesadaran metakognitif mampu untuk mengontrol aktivitas kognitifnya seperti menyusun lingkungan belajar dan memilih strategi untuk dalam menyelesaikan masalah, memantau proses penyelesaian masalah dan mengevaluasi seluruh kinerjanya. Kondisi tersebut yang membantu mahasiswa dalam proses konstruksi pemahaman. Anderson \& Nashon (2006) juga melaporkan bahwa kemampuan metakognisi yang dimiliki mahasiswa dapat meningkatkan kapasitas belajar yang penuh makna serta membantu mahasiswa mengonstruksi pemahaman. Kesadaran metakognitif berperan dalam peningkatan hasil belajar mahasiswa sehingga dengan kesadaran metakognitif yang tinggi menunjukkan kemampuan akademik yang bagus, sebaliknya mahasiswa dengan kesadaran metakognitif rendah menunjukkan kemampuan akademik yang kurang bagus (Coutinho, 2007).

Berdasarkan skor rata-rata dapat dilihat bahwa kedua kelas memiliki rata-rata kesadaran metakognitif yang sudah berkembang baik. Kesadaran metakognitif kelas eksperimen dan kelas kontrol sama-sama sudah berkembang dengan baik. Hal ini dikarenakan pada kelas eksperimen dan kelas kontrol sama-sama menggunakan pembelajaran berbasis masalah (problem based learning). Model problem based learning dapat mengembangkan kesadaran metakognitif mahasiswa. Model problem based learning menghasilkan produk kognisi yang lebih runtut dan sistematis dengan melaksanakan serangkaian prosedur sebelum mengonstruk pengetahuan, seperti mencari informasi penting, meringkas ide utama, merumuskan masalah, membuat hipotesis, mencari solusi permasalahan, dan menjabarkan alur pemerolehan konsep. Kebiasaan prosedural yang dilatih secara kontinu pada saat mahasiswa mengerjakan soal dan tugas.

Kesadaran metakognitif merupakan bagian penting dari pengajaran dan pembelajaran dengan model problem based learning. Pada pembelajaran spektroskopi atom kesadaran metakognitif diperlukan saat mahasiswa menyelesaikan dan mencari solusi masalah yang diberikan. Peran penting metakognitif dalam menyelesaikan masalah misalnya ketika mahasiswa dihadapkan dalam suatu masalah, maka mahasiswa tersebut dengan kesadaran metakognitifnya bertanya pada diri sendiri apa saja strategi yang akan dilakukan untuk menjawab masalah tersebut? Apa strategi-strategi kemungkinan penyelesaian masalah tersebut? Serta mengapa memilih strategi tersebut? Jika kesadaran metakognitif tersebut telah tumbuh maka mahasiswa terbantu dalam memecahkan masalah yang dihadapi. Hal ini menunjukkan adanya proses berpikir dalam diri mahasiswa untuk mencapai tujuan dalam belajarnya.

Blended learning dalam Problem Based Learning dapat membantu mahasiswa dalam mempermudah memecahkan suatu topik permasalahan yang diberikan. Mahasiswa memperoleh informasi tidak hanya dari buku panduan dan penjelasan guru saja tetapi bisa diakses dari berbagai sumber menggunakan jaringan internet. Sehingga mahasiswa secara berkelompok lebih kritis dalam mencari solusi permasalahan yang tepat. Mahasiswa memiliki kesadaran metakognitif mampu untuk mengontrol aktivitas kognitifnya, seperti menyusun lingkungan belajar dan memilih strategi untuk dalam menyelesaikan masalah, memantau proses penyelesaian masalah dan mengevaluasi seluruh kinerjanya. Kondisi tersebut membantu mahasiswa dalam proses konstruksi pemahaman yang terdapat di setiap fase-fase model problem based learning. Kemampuan metakognitif yang dimiliki mahasiswa dapat meningkatkan kapasitas belajar yang penuh makna serta membantu mahasiswa mengonstruksi pemahaman. 


\section{SIMPULAN}

Berdasarkan hasil penelitian ini dapat disimpulkan bahwa penerapan model pembelajaran problem based learning berbantuan blended learning dapat meningkatkan kesadaran metakognitif mahasiswa. Kesadaran metakognitif mahasiswa yang dibelajarkan dengan menggunakan model pembelajaran problem based learning berbantuan blended learning lebih tinggi dibandingkan pada kelas yang dibelajarkan dengan model problem based learning. Berdasarkan skor rata-rata dapat dilihat bahwa kedua kelas memiliki rata-rata kesadaran metakognitif yang sudah berkembang baik.

Kemampuan metakognitif mahasiswa juga dapat dilihat dari pengetahuan metakognitif, misalnya dengan menerapkan suatu model pembelajaran yang mengarahkan mahasiswa untuk membangun konsepnya sendiri dan peningkatan antar koneksi kognisi dalam sistem metakognisinya dengan cara menambahkan unsur-unsur multi representasi (makroskopis, submikroskopis, dan simbolik).

\section{DAFTAR RUJUKAN}

Anderson, D., \& Nashon, S. (2006). Predators of Knowledge Construction: Interprenting Students' Metacognition in an Amusement Park Physics Program. Science Education, 91(2), 298-320. https://doi.org/10.1002/sce.20176.

Arends, R. I. (2012). Learning to Teach. $9^{\text {th }}$ Edition. New York: McGraw-Hill.

Coutinho, S. (2007). The Relationship Between Goals, Metacognition, and Academic Sucsess. Educate Journal, 7(1), 39 -47.

Delialioğlu, Ö. (2012). Student Engagement in Blended Learning Environments with Lecture-Based. Educational Technology \& Society, 15(3), 310-322.

Delialioglu, O., \& Yildirim, Z. (2007). Students' Perceptions on Effective Dimensions of Interactive Learning in a Blended Learning Environment. Educational Technology \& Society, 10(2), 133-146.

Dobrzański, L. A., \& Brom, F. (2008). E-Learning on the Example of Materials Science. Journal of Achievements in Materials and Manufacturing Engineering, 29(1), 99-102.

Goodnought, K., \& Cashion, M. (2003). Fostering Inquary Through Problem Based Learning. The Sciense Teacher, 70(9), 2125.

Hmelo-Silver, C. E. (2004). Problem-Based Learning: What and How do Students Learn? Educational Psychology Review, 16(3), 235-266. doi:10.1023/B:EDPR.0000034022.16470.f3.

Ibrahim, M., \& Nur, M. (2000). Pengajaran Berdasarkan Masalah. Surabaya: Unesa University Press.

Kaku, M. (2011). Physycs of The Future: How Science Will Shape Human Destiny and Our Daily Lives by The Year 2100. New York: Knopf Doubleday Publishing Group.

Rusman., Kurniawan D., \& Riyana C. (2012). Pembelajaran Berbasis Teknologi Informasi dan Komunikasi: Mengembangkan Profesionalitas Guru. Jakarta: PT. Raja Grafindo Persada.

Schraw, G. (2007). The Use of Computer-Based Environments for Understanding and Improving Self-Regulation. Metacognition Learning, 2007(2), 169-176.

Strambi, A., \& Bouvet, E. (2003). Flexibility and Interaction at A Distance: A Mixed-Mode Environment for Language Learning. Language Learning \& Tecnology, 2003(73), 81-102.

Ward, J. D. \& Lee, C. L. (2002). A Review Problem Based Learning. Journal of Family and Consumer Sciences Education, $2(1), 16-25$.

Wonorahardjo, S. (2013). Pengantar Kimia Analitik Modern. Malang: Universitas Negeri Malang. 